\title{
Walk This Way: Ingroup Norms Determine Voting Intentions for Those
}

\section{Who Lack Sociopolitical Control}

Anna Potoczek, ${ }^{1}$ Marcin Bukowski, ${ }^{1}$ Soledad de Lemus, ${ }^{2}$ Gloria Jiménez Moya, ${ }^{3}$

\author{
Álvaro Rodríguez López, ${ }^{2}$ Katarzyna Jaśko ${ }^{1}$ \\ Manuscript accepted for publication in the \\ Personality and Social Psychology Bulletin
}

\author{
${ }^{1}$ Institute of Psychology of the Jagiellonian University \\ ${ }^{2}$ Mind, Brain and Behavior Research Center at the University of Granada (CIMCYC-UGR) \\ ${ }^{3}$ Centre for Social Conflict and Cohesion Studies, Pontifical Catholic University of Chile
}

\section{Author Note}

Anna Potoczek https://orcid.org/0000-0002-3293-249X

Correspondence concerning this article should be addressed to Anna Potoczek, Institute of Psychology, Jagiellonian University, Ingardena 6, 30-060 Kraków, Poland. Email: anna.potoczek@gmail.com.

This research was supported by a grant number 2014/15/G/HS6/04529 awarded by the Polish National Science Centre to the second author, as well as by two grants for young researchers financed by the Faculty of Philosophy of the Jagiellonian University awarded to the first author. It was also supported by Grant no.PID2019-111549GB-I00 funded by MCIN/AEI/10.13039/501100011033 awarded to the third author. 


\begin{abstract}
Even though taking part in elections is one of the most direct tools to influence the socio-political system, many people choose not to vote. Research shows that this problem is especially prevalent among those citizens who do not believe they have control over social and political issues, but the question remains as to what could encourage their voting behavior. We predicted that individuals who experience low levels of control can be more susceptible to ingroup norms regarding participation in political elections than those with a high sense of sociopolitical control. Across six studies we found consistent support for this hypothesis. Specifically, people who experience decreased sociopolitical control were more likely to vote when descriptive norms (measured or manipulated) were conducive to voting. The results have important theoretical and applied implications, illuminating the boundary conditions under which people deprived of control can still be motivated to participate in a political sphere.
\end{abstract}

Keywords: norm conformity, sociopolitical control, voting intentions 
Voting in political elections is a central tool to influence social and political reality. Therefore, it is crucial to know what motivates people to participate in them and what accounts for their apathy and disengagement. Past research has shown that willingness to take part in elections is related to higher levels of perceived control over sociopolitical affairs. Specifically, those who believe that they as citizens can influence political decisions and feel responsible for them are also more likely to vote (Paulhus \& Christie, 1981). In contrast, a higher external locus of control, which reflects low levels of personal control, is related to social and political alienation (Twenge et al., 2004). In the current research we examine social factors, such as ingroup norms, that may nonetheless encourage people with low levels of perceived sociopolitical control to vote.

\section{Sense of Control and Voting}

Past conceptualizations of sense of control consistently suggest that it is a heterogeneous construct (Rothbaum et al., 1982; Skinner, 1996). For instance, Paulhus and Christie (1981) argued that people can experience control (or a lack thereof) in three different and conceptually independent spheres. Firstly, people can experience control over their own actions and achievements, which is described as personal control. Secondly, they can feel control over their interactions with other people - this sphere was labeled by the authors as interpersonal control. Finally, people may differ in the feelings of control over the political and social system. Perceived control in this sphere is termed as sociopolitical control (SPC) and it positively predicts a variety of indices of political engagement, such as participation in local politics, voting, writing letters to politicians or boycotting products (Paulhus \& Christie, $1981)^{1}$. Similarly, perceptions of general self-efficacy, directly related to sense of control, are

\footnotetext{
${ }^{1}$ The construct of sociopolitical control is related to that of political self-efficacy, however, there are some important differences between them. First, scales of the latter construct measure whether an individual believes he or she can influence political affairs on their own and, second, they are limited strictly to the political life of the country (e.g., Craig et al., 1990). On the contrary, sociopolitical control scale measures control on the collective level ("we, the voters", "we, as consumers" etc.) and captures a variety of beliefs, not only restricted to politics (e.g., control that people have over economy, business or wars).
} 
predictive of actual voting behavior (Condon \& Holleque, 2013). Likewise, a more specific construct of perceived efficacy in the political sphere has been shown to be a robust predictor of voting intentions (Karp \& Banducci, 2008). Additionally, an individual's perception of their competence as a political actor combined with a belief that the political system is responsive to citizens' demands was shown to be strongly related to voting probability (Pollock, 1983). Finally, research shows that those citizens who experience very high levels of control over the result of the elections (they perceive an inflated probability of casting a decisive ballot) are more likely to vote in the elections (Darmofal, 2010).

Whereas the main effect of a sense of control over politics on voting has already been established, it is still not clear under what conditions people who experience low control over their personal and socio-political environments would engage in political elections. At the same time, research shows that when people feel deprived of control, they are more likely to conform to the salient social norms of their ingroup (Barth et al., 2017; Jonas \& Fritsche, 2012; Stollberg et al., 2017). However, no research so far has considered the interactive effect of individual differences in perceived sociopolitical control and group norms on voting intentions. Combining these two insights, we propose that even those who have low sociopolitical control can nonetheless feel motivated to vote when they are surrounded by a positive, participatory social norm.

\section{Social Norms and Voting Intentions}

In general, when it comes to voting, people are influenced by the behavior of their community. For instance, Bond and colleagues (2012) demonstrated that exposing subjects to examples of their friends who had already taken part in the elections increased chances of voting and this effect was further spread in social networks. These results are in line with earlier research showing that voting is contagious, such that encouraging a single person to vote increases chances of casting a ballot by their significant other (Nickerson, 2008) and it 
may influence on average, at least four other people's decision whether to vote or not (Fowler, 2005). This is also one of the reasons why highlighting a negative descriptive norm which states that most people do not vote - a strategy often employed by authorities and media - is not effective and it may impair rather than improve actual voting turnout (Cialdini et al., 2006; Gerber \& Rogers, 2009). Specifically, when people are presented with information that the majority of their ingroup members are not active voters, they may conclude that not taking part in elections is commonly accepted and approved by their ingroup. In sum, the existing literature suggests that people's voting behavior is strongly affected by whether other people in their social environment vote or not.

However, Gerber and Rogers (2009) found that presenting participants with a positive descriptive norm, which suggested that turnout among citizens of the same state was increasing, affected only those who were infrequent voters. Frequent voters showed no differences in their intention to vote. This initial evidence may suggest that infrequent, and presumably more apathetic, voters might be more strongly influenced by ingroup voting norms, not revealing the underlying psychological mechanism that accounts for these effects. In our research we propose that low sociopolitical control voters can be more easily influenced by ingroup voting norms, especially norms that are present in their reference group. Additionally, the influence of the norm among participants' family and acquaintances regarding voting intentions was demonstrated to be even stronger and universal (Gerber et al., 2008; Gerber \& Rogers, 2009). These results are in line with the self-categorization theory (Turner et al., 1987), according to which groups that are closer to one's self have a greater impact on behavior.

Based on this knowledge, in the current research we decided to measure compliance to social norms of the ingroup operationalized on two different levels: the whole nation and participants' acquaintances. We assumed that lack of control should increase conformity to 
both kinds of norms, but we also wanted to explore whether the effect would be stronger for the ingroup defined as acquaintances.

\section{Compliance to Social Norms When Lacking Control}

When people's sense of control is threatened, they are motivated to restore it (Rothbaum et al., 1982) and one way to do so is to turn to social groups and to their norms. For example, low (vs. high) power participants are more likely to be influenced by opinions of other people (Galinsky et al., 2008), and to adhere to social norms (Lammers et al., 2010). In addition, the less competent people feel, the more they obey the rules imposed on them (Lucas \& Lovaglia, 2014; Milyavsky et al., 2020). In sum, this evidence suggests that when people feel low in agency and do not know how to act, then they are more vigilant to cues signaling what other people do and tend to behave in the same way.

Research also shows that increased norm compliance occurs when an individual's motive of personal control is endangered. For instance, Stollberg, Fritsche and Jonas (2017) showed that when low control was salient, people were more prone to follow the ingroup (but not outgroup) norms they were presented with. In a similar vein, lack of control over environmental threat increased group protective behavior and conformity to ingroup norms (Barth et al., 2017). These results are explained by the group-based control model (Fritsche et al., 2011, 2013), which states that threat to personal control increases people's willingness to activate their social self by thinking and acting as group members. Parallelly, supporting the view that lack of control results in increased norm compliance, numerous studies have shown that mortality salience leads to increased following of group norms (Fritsche et al., 2010; Gailliot et al., 2008; Jonas et al., 2008).

Taken together, this research suggests that threatened perceptions of control over their environment make people more susceptible to salient social norms. Drawing on this literature, the aim of our research was to answer the question of whether participatory social norms can 
be used to motivate people with internalized low levels of sociopolitical control to vote. The novelty of this research resides in examining whether increased norm compliance is not only a response to a threatened sense of control, but also a characteristic typical for people who are chronically low in their feelings of sociopolitical control (Paulhus \& Christie, 1981). Whereas previous research has mainly concentrated on the personal level of control as a predictor of norm compliance, we propose that in the specific domain of voting behavior, a sense of sociopolitical control might be a crucial predictor of norm following intentions related to voting.

In sum, to the best of our knowledge, this would be the first research to address the problem of whether it is possible to decrease voter apathy among participants with low sociopolitical control levels, using positive participatory norms. We base this assumption on both research demonstrating increased norm compliance under lack of control and on evidence showing that influencing perception of norms can be a successful way of changing patterns of social behavior (for a review, see Tankard \& Paluck, 2016).

\section{Current Research}

In a set of six studies conducted in different social contexts we measured perceptions of voting norms among ingroup members or manipulated those perceptions. Each time we asked about social norms with regard to two reference groups - the whole nation and participants' acquaintances. Across all studies we tested the hypothesis that participants with low (vs. high) sociopolitical control levels would be more likely to conform to the ingroup norm, i.e., when the voting ingroup norm was strong, they would tend to vote more than when the ingroup voting norm was weak. In Study 1 this was an exploratory hypothesis, while in the remaining studies it was confirmatory. Across studies 1a, 1b, 2 and 3 we offer correlational evidence for our claims, while in studies 4 and 5 we provide additional experimental support for our main hypotheses. 


\section{Study 1}

We conducted this study in parallel in two countries - Poland (Study 1a) and Spain (Study 1b) to check whether the effects generalize across contexts. Our main preregistered hypothesis was that there would be an interaction between perceived personal control and the voting norm on voting intentions such that those who perceive less control would rely more on group norms. Data, syntaxes and codebook for all the studies are available at https://osf.io/m8vby/. Preregistration for this study is available at https://osf.io/uc2yw.

\section{Method}

\section{Participants}

Expecting relatively small effect sizes, we recruited at least 350 participants in each country. In Study 1a, 482 Polish participants recruited from the platform ResearchOnline completed the procedure in exchange for monetary compensation ${ }^{23}$. We excluded 105 participants who failed to fill in at least one of the attention checks properly ${ }^{4}$ and two participants who were not Polish. This left us with a final sample of 375 participants (148 male, 226 female, 1 other; $\left.M_{\text {age }}=39.92, S D=12.01\right)$. In Study $1 b, 403$ Spanish participants were recruited through an academic mailing list in exchange for participating in a lottery. We excluded 23 participants who failed to fill in at least one of the attention checks properly and 27 participants who were not Spanish. This left us with a final sample of 353 participants (104

\footnotetext{
${ }^{2}$ In each study conducted in Poland the company received around 10 PLN ( 2.5 USD) for each participant, while the company in Chile - 1.5 Euro ( 1.8 USD) for each participant. In Spain participants took part in a lottery.

${ }^{3}$ For studies 1a, 2, 3, and 4 we used the services of ResearchOnline (http://researchonline.pl/) and Pollster (https://pollster.pl/), Polish research platforms with expertise in recruiting participants of different gender, age, education level, and political beliefs across the country. Pollster has a research panel with nationwide coverage, so it was preferred for studies 2-4. In Study 5 (Chile) we used the services of Netquest (https://www.netquest.com/) that offers broad access to Chilean participants ( $>61000)$. Each of the companies provided high-quality data and tried to make the sample as representative for the given country population as possible using online participants. In each of them, participants are being compensated for their work, depending on the time and effort that needs to be invested in filling in a given survey.

${ }^{4}$ We decided to include attention checks in all of our studies based on the results by Oppenheimer et al. (2009), who reported that in psychological studies 14 to $46 \%$ of participants fail to read and follow the instructions in the experiment. Authors demonstrated that excluding such participants from the dataset increases its reliability, statistical power and overall validity of the data.
} 
male, 247 female, 2 other; $M_{\text {age }}=24.83, S D=7.61$ ). We conducted a sensitivity analysis using $G^{*}$ Power (Faul et al., 2007) and found that with such a sample, the minimum effect that we could detect $(\alpha=.05$ and $1-\beta=.80)$ was $f=.03$ for both studies $1 \mathrm{a}$ and $1 \mathrm{~b}$.

\section{Materials and Procedure}

We conducted this study on-line two weeks before the elections for the European Parliament in Poland and in Spain in 2019. We informed participants they were taking part in the study on different experiences and aspects of social life. Afterwards we asked them to fill in the following scales.

Spheres of control. Participants filled in two subscales from the spheres of control scale (Paulhus \& Van Selst, 1990): personal control (10 items, e.g., "I can usually achieve what I want when I work hard for it", “Once I make plans, I am almost certain to make them work", Study 1a: $\alpha=.78$, Study 1b: $\alpha=.74)$ and socio-political control (10 items, e.g., "By taking an active part in political and social affairs we, the people, can control world events", "The average citizen can influence government decisions", Study 1a: $\alpha=.76$, Study 1b: $\alpha=$ $.71)$.

Perceived voting norms. Afterwards participants estimated the percentage of their ingroup members that would take part in elections for the European parliament using two separate items: "In your opinion, what percentage of Poles (Spaniards) will vote in the next elections on May 26?". The same question but with regard to the group "people you know" was used to elicit the acquaintances voting norm. Participants gave their answers on a slider ranging from 0 to $100 \%$.

Voting intentions. We used two items: "What is the probability that you will vote in the upcoming elections for the European Parliament on the scale from 0 (I am sure I won't vote) to 100 (I am sure I will vote)?" and "How important is it for you to vote in the 
upcoming elections to European Parliament on the scale from 0 (not at all) to 100 (very much)?" (Study 1a: $r=.87, \alpha=.93$, Study 1b: $r=.50, \alpha=.67$ ).

Attention checks. We used two attention checks: "If you're reading this please choose number two". We included similar attention checks in all of the described studies ${ }^{5}$.

\section{Results}

\section{Confirmatory analyses - personal control as a moderator}

National voting norm. First, we examined the main effects of personal control and perceived voting norm on voting intentions. In Study 1a, both variables were significant predictors of voting intentions (Personal control: $b=4.46,95 \%$ CI $[0.42,8.50], \beta=.11, p=$ .031 , Voting norm: $b=0.43,95 \%$ CI $[0.19,0.67], \beta=.18, p<.001)$. We then added an interaction between personal control and perceived voting norm, but it was non-significant $(b$ $=-0.15,95 \%$ CI $[-0.42,0.13], p=.296 ; R^{2}$ change $\left.<.01\right)$.

In Study 1b, the effect of personal control on voting intentions was not significant $(b=$ $3.15,95 \% \mathrm{CI}[-0.39,6.70], \beta=.09, p=.081)$, but perceived social norm was a significant predictor $(b=0.29,95 \% \mathrm{CI}[0.12,0.46], \beta=.18, p=.001)$. However, the interaction between the two variables was non-significant as well $\left(b=0.16,95 \%\right.$ CI $[-0.07,0.40], p=.169 ; R^{2}$ change $<.01)^{6}$.

Acquaintances voting norm. Then, we examined the main effect of perceived acquaintances voting norm on voting intentions. It was a strong and significant predictor in Study 1a $(b=0.71,95 \%$ CI $[0.59,0.83], \beta=.52, p<.001)$ and Study $1 \mathrm{~b}(b=0.34,95 \%$ CI $[0.24,0.45], \beta=.34, p<.001)$. However, an interaction between personal control and perceived voting norm was non-significant in both studies (Study 1a: $b=-0.03,95 \%$ CI [-

\footnotetext{
${ }^{5}$ Apart from the hypotheses and scales described in the main text in each of the studies we tested different hypotheses using several additional scales not related to the purpose of this paper. All of them are reported in the Supplementary materials.

${ }^{6}$ Descriptive statistics and correlation coefficients for the main variables in all studies are included in Tables 1-6 in the Supplementary materials.
} 
$0.17,0.11], p=.689 ; R^{2}$ change $<.01 ;$ Study $1 \mathrm{~b}: b=0.06,95 \%$ CI $[-0.07,0.18], p=.361 ; R^{2}$ change $<.01)^{7}$.

\section{Exploratory analyses - sociopolitical control as a moderator}

In subsequent exploratory analyses we examined whether the hypothesized interaction would occur for sociopolitical control and social norms.

National voting norm. The main effect of sociopolitical control on voting intentions was significant (Study 1a: $b=13.49,95 \%$ CI [9.75, 17.24], $\beta=.34, p<.001$; Study 1b: $b=$ $8.46,95 \%$ CI $[5.33,11.60], \beta=.27, p<.001)$. Next, we added an interaction between sociopolitical control and perceived voting norm, which was significant for Study 1a $(b=-$ $0.51,95 \%$ CI $[-0.80,-0.21], p<.001 ; R^{2}$ change $\left.=.03\right)$. The simple slope analysis revealed that the effect of national social norm was a significant and positive predictor for participants who scored low on sociopolitical control $(b=0.78,95 \%$ CI $[0.47,1.09], \beta=.33, p<.001)$, but this effect was not significant among those who scored high on sociopolitical control $(b=$ $-0.09,95 \%$ CI $[-0.45,0.28], \beta=-.04, p=.641)^{8}$. See Figure 1 . This interaction was not significant for Study $1 \mathrm{~b}(b=-0.08,95 \%$ CI [-0.27, 0.12$], \beta=-.04, p=.437)$.

\footnotetext{
${ }^{7}$ We did not include any covariates in the models reported in this manuscript.

${ }^{8}$ In each study we understand "low" and "high" as -1SD and +1SD of the moderator. We computed conditional effects of the predictor at different values of the moderator using PROCESS macro (Hayes, 2018).
} 


\section{Figure 1}

The Interaction Between Sociopolitical Control and Perceived National Voting Norm on Voting Intentions in Study 1 a

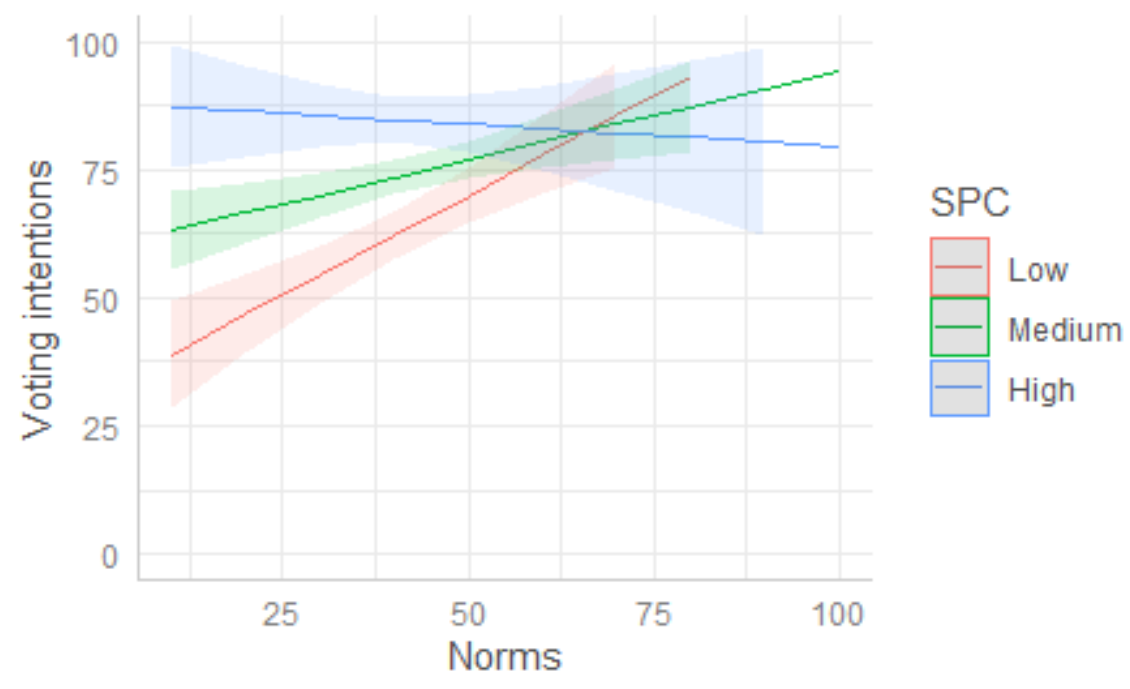

Note: On each figure in this paper describing correlational data shades around the lines illustrating slopes depict $95 \%$ confidence intervals. To create the graphs we used ggplot2 package (Wickham, 2016) and ggeffects package (Lüdecke, 2018).

Acquaintances voting norm. We repeated the analyses using the norms of participants' acquaintances. The interaction was significant for Study $1 \mathrm{a}(b=-0.23,95 \%$ CI [$0.37,-0.10], p<.001 ; R^{2}$ change $=.02$ ). Further analysis revealed that the effect of ingroup norm was stronger for participants who scored low on sociopolitical control $(b=0.82,95 \%$ CI $[0.67,0.98], \beta=.59, p<.001)$, than among those who scored high on sociopolitical control $(b=0.43,95 \% \text { CI }[0.26,0.60], \beta=.30, p<.001)^{9}$. See Figure 2. The pattern was

\footnotetext{
${ }^{9}$ For detailed statistics including statistical significance transition points and percentage of participants scoring below these points (based on Johnson-Neyman output in PROCESS macro) see Table 7 in the Supplementary materials.
} 
similar although it was not significant for Study $1 \mathrm{~b}(b=-0.10,95 \%$ CI $[-0.21,0.01], p=.087$; $\mathrm{R}^{2}$ change $\left.=.01\right)^{1011}$.

\section{Figure 2}

The Interaction Between Sociopolitical Control and Perceived Acquaintances Noting Norm on Voting Intentions in Study la

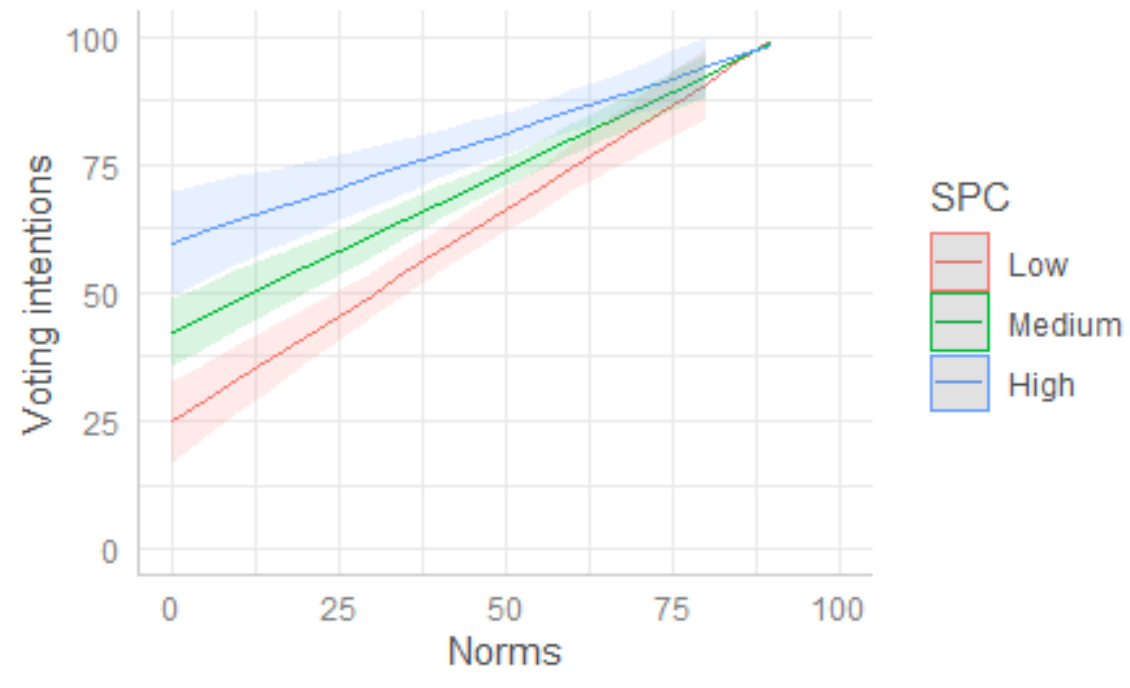

\section{Discussion}

The aim of Study 1 was to test whether participants who experience a chronic lack of control would be more likely to follow the ingroup norm when it comes to voting. We did not find support for this hypothesis in the domain of personal control. We did find, however, that people who lack sociopolitical control depended more strongly on the ingroup norm, both when it came to the norm of the ingroup in terms of the whole nation (in Study 1a) and their

\footnotetext{
${ }^{10}$ For exploratory reasons we conducted an analysis for voting importance and voting probability separately. The subsequent analysis revealed that there was no significant interaction between sociopolitical control and norm for voting importance $(b<0.01,95 \%$ CI $[-0.13,0.13], p=.985)$ but there was a significant interaction for voting probability $(b=-0.20,95 \%$ CI $[-0.34,-0.06], p=.004)$. Same as in study $1 \mathrm{a}$, the influence of acquaintances voting norm was a stronger predictor for participants who scored low on sociopolitical control $(b=0.61,95 \% \mathrm{CI}$ $[0.45,0.77], \beta=.50, p<.001)$, than among those who scored high on sociopolitical control $(b=0.29,95 \% \mathrm{CI}$ $[0.14,0.45], \beta=.24, p<.001)$.

${ }^{11}$ We additionally checked whether the results of the studies are not due to differences in participants' political orientation, adding this variable as a covariate in all of the studies. The main pattern of the results remained unchanged. Therefore, we did not further include these variables in the model when describing the results.
} 
close acquaintances (in both studies). This effect was tested in two different countries parallelly, although in Spain it occurred only for voting probability and the acquaintances voting norm. This might have happened because Spain is a much less homogeneous country at the national level than Poland, with many differentiated and highly influential regional identities that might reduce the impact of national level norms (e.g., Rodríguez \& Moya, 1998).

\section{Study 2}

The initial aim of Study 2 was to replicate the results of Study 1 using an experimental manipulation of the social norm in the context of legislative elections. Specifically, we randomly assigned participants to a low vs. high turnout condition and informed them that their ingroup members are the least vs. most active voters. For the ingroup we chose people of the same age (between 30 and 45 years old). As in reality voting turnout in Poland is highest among old people and lowest among young people, we assumed it would be most credible to manipulate the norm of the group that is the most neutral in terms of voting probability, namely middle-aged people. We predicted that participants with low (vs. high) sociopolitical control levels would be more likely to conform to the ingroup norm. Preregistration for this study is available at https://osf.io/n4q6u.

\section{Method}

\section{Participants}

Three hundred nineteen participants recruited from the platforms ResearchOnline and Pollster completed the online study in exchange for monetary compensation. We excluded 93 participants who failed to fill in properly at least one of the attention checks, 26 participants who were younger than 30 or older than 45 , two participants who admitted they had not read the article in the manipulation task, 39 participants who were not able to properly answer the comprehension check, and three participants who admitted they did not have voting rights. All 
of the exclusion criteria were preregistered. This left us with a final sample of 156 participants (72 male, 84 female, $M_{\text {age }}=37.03, S D=4.80$ ). Exclusions did not change the pattern of the results. Sensitivity analysis showed that with this sample size the minimum effect that we could detect for $\alpha=.05$ and $1-\beta=.80$ was $f=.07$.

\section{Materials and procedure}

We conducted the study on-line four months before the general legislative elections in Poland in 2019.

Spheres of control. At the beginning of the experiment participants filled in two subscales from the spheres of control scale: personal control subscale $(\alpha=.82)$ and sociopolitical control subscale $(\alpha=.79)$.

Norm manipulation. Next, we randomly assigned participants to one of the two conditions (strong vs. weak norm) and asked them to read an article titled "Young adults are likely (vs. not likely) to vote. People aged between 30 and 45 are the most (vs. least) active voters". The article described the results of research on voting intentions conducted by experts in the field of political science stating that, depending on the condition, young adults are much more (vs. much less) likely to vote than people in other age groups.

Reading check. Next, we asked participants whether they read it using a yes/no question.

Comprehension check. To make sure participants understood the content of the article we asked them to rank age groups from the most to the least active voters. In the final sample we included only participants who classified their age group as most active in the "strong norm" condition and as least active in the "weak norm" condition.

Voting intentions. We measured participants' voting intentions with the same items as in Study $1(r=.92, \alpha=.96)$. 
Perceived voting norms. Afterwards participants estimated the percentage of their ingroup members that would take part in the elections to Polish parliament as in Study 1.

Demographics. At the end of the questionnaire participants answered questions about their sex, age, occupation, and education level. We also asked participants whether they had voting rights.

\section{Results}

First, we examined the main effects of our independent variables on declared voting intentions. Sociopolitical control was a significant predictor $(b=12.85,95 \%$ CI $[8.57,17.14]$, $\beta=.43, p<.001)$, but the effect of manipulation was not significant $\left(\mathrm{M}_{\text {weak norm }}=85.98\right.$, $\left.\mathrm{M}_{\text {strong norm }}=79.98, b=-6.52,95 \% \mathrm{CI}[-14.00,0.95], \beta=-.13, p=.087\right)$. We then added an interaction between sociopolitical control and manipulation of norm on voting intentions, which was non-significant, $b=0.79,95 \%$ CI [-7.81, 9.39], $p=.857, R^{2}$ change $<.01$.

National voting norm. In the next step we checked whether our hypothesis can be supported using measured, not manipulated norms as a predictor. Whereas the main effect of national voting norm on voting intentions was not significant $(b=0.31,95 \%$ CI [-0.05, 0.67], $\beta=.12, p=.095)$, an interaction between sociopolitical control and voting norm was significant $\left(b=-0.51,95 \%\right.$ CI $[-0.92,-0.10], p=.014 ; R^{2}$ change $\left.=.03\right)$. The simple slope analysis showed that the effect of national social norm was positive and significant for participants who scored low ( $b=0.63,95 \% \mathrm{CI}[0.19,1.07], \beta=.25, p=.005)$, but not for those who scored high on sociopolitical control $(b=-0.26,95 \%$ CI $[-0.84,0.32], \beta=-.11, p=$ .370). See Figure 3. 


\section{Figure 3}

The Interaction Between Sociopolitical Control and Perceived Voting Norm on the National Level on Voting Intentions in Study 2

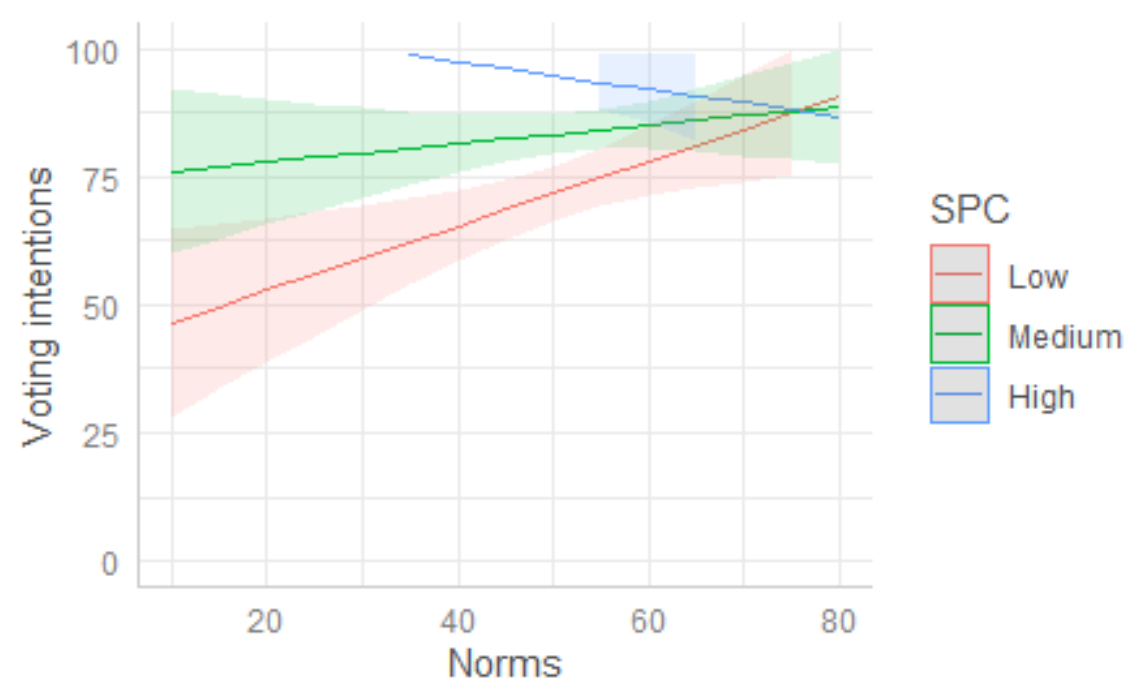

Acquaintances voting norm. We repeated this analysis for the acquaintances voting norm. The main effect of norms was significant $(b=0.49,95 \%$ CI $[0.34,0.64], \beta=.42, p<$ $.001)$. An interaction between this norm and sociopolitical control was also significant $(b=-$ $0.27,95 \%$ CI $[-0.42,-0.12], p<.001 ; R^{2}$ change $\left.=.05\right)$. A subsequent analysis revealed that the acquaintances voting norm was a significant predictor of voting intentions among participants who scored low on sociopolitical control $(b=0.67,95 \%$ CI $[0.49,0.85], \beta=.58$, $p<.001)$, but not significant among those who scored high on sociopolitical control $(b=0.20$, $95 \%$ CI $[-0.01,0.41], \beta=.17, p=.067)^{12}$. See Figure 4 .

\footnotetext{
${ }^{12}$ Reported analyses were conducted on the data collapsed across conditions. When we repeated analyses separately for each condition, it occurred that interaction with national norm as predictor was significant only in the weak norm condition, while on the other hand interaction with norm among friends as predictor was significant only in the strong norm condition. Although these interactions were not significant in the other conditions $(p s<.16)$, the pattern of the results was very similar. The lack of significance was probably due to not enough power to detect the effect in the split sample.
} 


\section{Figure 4}

The Interaction Between Sociopolitical Control and Perceived Voting Acquaintances Voting

Norm on Voting Intentions in Study 2

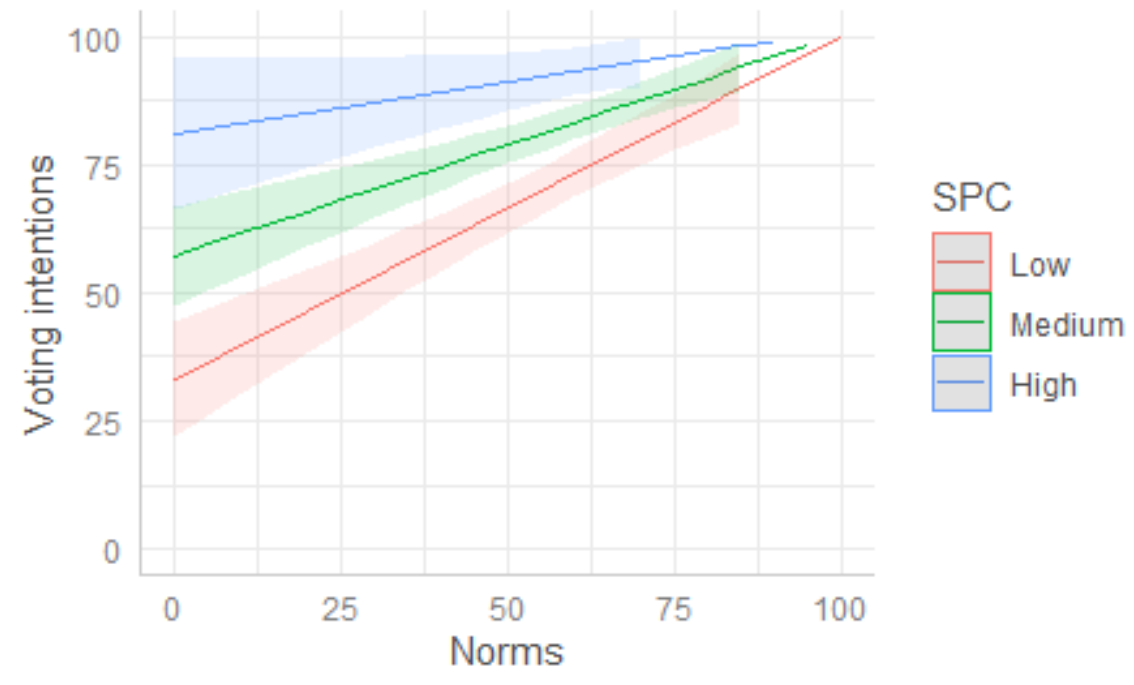

\section{Discussion}

In Study 2 we did not find the predicted effect of our experimental manipulation on voting intentions, which might be due to the type of ingroup (i.e., age group) used. It is possible that people think of themselves rather in terms of the roles they play and more established groups they belong to (e.g., based on nationality, ethnicity, etc.) rather than an arbitrarily specified age group, which is not based on common identity or shared values and in a highly polarized political context like Poland it may not provide any useful guidance to people low in control. Indeed, we not only observed a lack of interaction, but also no direct influence of norm manipulation on voting intentions. However, when we performed the analysis using the perceived norm as a predictor, we found the expected interaction pattern that replicated the findings of Study 1. Specifically, people who scored low (vs. high) on sociopolitical control were more likely to depend on ingroup norms in terms of voting.

\section{Study 3}

In Study 2 we did not find an effect of our manipulation and this could be due to the fact that information about the age group was not informative enough to help to regain control 
by following the group norm. Thus, we conducted a correlational study in the context of Polish presidential elections to check whether acquaintances and national norms in such a polarized context would still influence willingness to vote among low SPC participants. To check whether our results can be obtained in yet another type of election, which were conducted in an even more polarized context, we administered the next correlational study just before the presidential elections in Poland in June 2020. At that time, Polish society was strongly divided - according to polls (and confirmed with actual results) half of society supported the president running for reelection, while the other half supported the opposition candidates. Again, we predicted that participants with low (vs. high) sociopolitical control levels would be more likely to conform to the ingroup norm. Preregistration for this study is available at https://aspredicted.org/2wi89.pdf.

\section{Method}

\section{Participants}

According to a previously conducted power analysis, to test linear multiple regression with an effect size between small and medium $(f=0.04, \alpha=.05,1-\beta=.90)$ and three predictors we needed 359 subjects. Four hundred eleven participants recruited from the platform Pollster completed the whole procedure of the study in exchange for monetary compensation. We excluded two participants who admitted they did not have voting rights. This left us with a final sample of 409 participants (214 males, 194 females, 1 other, $M_{\mathrm{age}}=$ 44.87, $S D=14.75)^{13}$.

\section{Materials and procedure}

We conducted this study online one week before the presidential elections in Poland in 2020.

\footnotetext{
${ }^{13}$ In this study, to avoid providing monetary compensation for participants who did not follow the instructions, we included the same attention check as in studies 1-2, which this time - in the case of not completing it properly - ended the procedure of the study right away. 36 participants who filled in the attention check improperly were not allowed to continue the study.
} 
Spheres of control scale. At the beginning of the experiment participants filled in two subscales from the spheres of control scale: personal control subscale $(\alpha=.73)$ and sociopolitical control subscale $(\alpha=.65)$.

Perceived voting norms. Next, participants estimated the social norm of voting in presidential elections in Poland separately for Poles and people they knew personally. Participants gave their answers on a slider ranging from 0 to $100 \%{ }^{14}$.

Voting intentions. We measured participants' voting intentions in the same way as in studies 1 and $2(r=.85, \alpha=.92)$.

\section{Results}

National norm. Both sociopolitical control and national voting norm were significant predictors of voting intentions (Sociopolitical control: $b=4.57,95 \%$ CI [1.62, 7.53], $\beta=.14$, $p=.002$; National norm: $b=0.62,95 \%$ CI $[0.43,0.81], \beta=.30, p<.001)$. However, an interaction between norm and control was non-significant, $b=0.02,95 \%$ CI $[-0.21,0.26], p=$ $.842\left(R^{2}\right.$ change $\left.<.01\right)$.

Acquaintances voting norm. The main effect of the perceived voting norm on voting intentions was significant $(b=0.50,95 \% \mathrm{CI}[0.40,0.60], \beta=.43, p<.001)$. The predicted interaction was significant as well $\left(b=-0.17,95 \%\right.$ CI $[-0.29,-0.05], p=.005, R^{2}$ change $=$ .02). Simple slopes analysis showed that the effect of ingroup norm was stronger for participants who scored low $(b=0.62,95 \%$ CI $[0.49,0.76], \beta=.54, p<.001)$, than for those who scored high $(b=0.36,95 \%$ CI $[0.22,0.50], \beta=.31, p<.001)$ on the sociopolitical control scale. See Figure 5.

\footnotetext{
${ }^{14}$ In this study we additionally measured perceived voting norms among government supporters and people opposing government. We were interested in whether in times of high political polarization people with low sociopolitical control levels will be more easily swayed by norms existing among the same political option supporters. We did not find support for this hypothesis in the data. A detailed description of the results is included in the Supplementary materials.
} 


\section{Figure 5}

The Interaction Between Sociopolitical Control and Perceived Acquaintances Voting Norm on Voting Intentions in Study 3

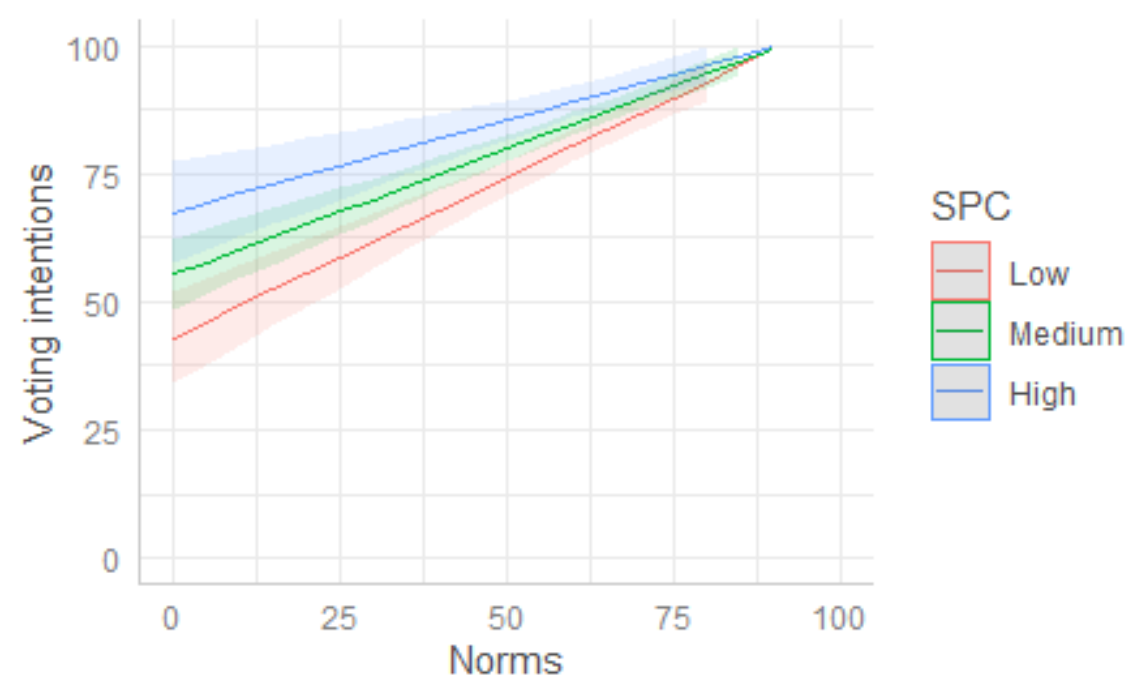

\section{Discussion}

In Study 3 we aimed at replicating the pattern of the results obtained in studies 1 and 2 in the context of different types of elections (presidential ones) in a more polarized context. Participants who scored low on the sociopolitical control scale were more likely to conform to the norm among their friends and acquaintances. This time, however, the national norm was not related to voting intentions differently for participants with particular sociopolitical control levels. This might be due to a very high polarization in Polish society at the time of the elections. It is possible that in such a context, the general national norm was no longer informative for participants or it was not treated by them as a point of reference, as it no longer represented their values.

\section{Study 4}

Study 2 showed correlational evidence of the effect of national norms on voting intentions amongst low SPC participants in the context of Polish legislative elections, however Study 3 showed no such effect in the context of more polarized presidential 
elections. In study 4 (conducted one week before legislative elections) we experimentally manipulated national norms to check their influence on Polish voters. Thus, the goal of Study 4 was to replicate previous findings with a revised manipulation. To that end, we performed a pilot study (described in detail in the Supplementary materials). In this experiment we changed the reference group in the manipulation task from an age group to a national group. We predicted that participants with low (vs. high) sociopolitical control levels would be more likely to conform to the national norm. In addition to manipulating the national norm we also measured perceived norms among participants' acquaintances. Here, we similarly predicted that participants with low (vs. high) sociopolitical control levels would be more likely to conform to the norm. Preregistration for this study is available at https://osf.io/hrvd7.

\section{Method}

\section{Participants}

We determined the sample size using $\mathrm{G}^{*}$ Power software. For a linear multiple regression test with an effect size between small and medium $(f=0.04, \alpha=.05,1-\beta=.80)$ and three predictors we obtained the number of 277 subjects. Three hundred eighty-two participants recruited from the platform Pollster completed the procedure of the study in exchange for monetary compensation. We excluded 57 participants who failed to fill in the attention check properly, one participant who admitted they did not read the article in the manipulation task, 56 participants who were not able to properly answer the comprehension check and two participants who admitted they did not have voting rights. This left us with a final sample of 266 participants (116 males, 149 females, 1 other, $\left.M_{\mathrm{age}}=46.94, S D=17.21\right)$.

\section{Materials and procedure}

We conducted the study on-line one week before the general legislative elections in Poland in 2019. 
Spheres of control. At the beginning of the experiment participants filled in two subscales from the spheres of control scale: personal control subscale $(\alpha=.76)$ and sociopolitical control subscale $(\alpha=.67)$.

Manipulation of group norms. Next, we randomly assigned participants to one of the two conditions. In the strong (vs. weak) voting norm condition participants read an article "Number of Poles likely to vote is increasing (vs. decreasing)" presumably published on the Polish Press Agency website. The full text of manipulation is included in the Supplementary materials.

Reading check. Next, we asked participants whether they read the article using a yes/no question.

Voting intentions. We measured participants' voting intentions with the same items as in previous studies $(r=.86, \alpha=.92)$.

Perceived voting norm. Afterwards participants estimated the percentage of their acquaintances that would take part in elections for the Polish parliament, which was analogous to Studies 1-3.

Comprehension check. To make sure participants understood the content of the article we asked them to state, according to what they had read, whether voting intentions among ingroup members are increasing, decreasing, or are the same. In the final sample we included only participants who indicated that voting intentions are increasing in the "strong norm" condition and that the voting intentions are decreasing in the "weak norm" condition.

Demographics. Demographics were measured as in Studies 2 and 3.

\section{Results}

National norm. Both sociopolitical control and manipulation of ingroup norm (coded as $0=$ weak norm, $1=$ strong norm) had a significant and positive effect on declared voting intentions (Sociopolitical control: $b=8.79,95 \%$ CI [5.59, 11.99], $\beta=.31, p<.001$; ingroup 
norm: $\left.\mathrm{M}_{\text {weak norm }}=84.84, \mathrm{M}_{\text {strong norm }}=91.80, b=7.27,95 \% \mathrm{CI}[2.06,12.48], p=.006\right)$. Next, we tested the interaction between norm and sociopolitical control, which was significant $(b=$ $-7.68,95 \%$ CI $[-14.12,-1.25], p=.019, \mathrm{R}^{2}$ change $\left.=.02\right)$. Subsequent analysis revealed that the effect of the manipulation was significant only for participants who scored low $(b=13.53$, 95\% CI [6.17, 20.89], $\beta=.30, p<.001)$, but not high $(b=1.09,95 \%$ CI $[-6.23,8.40], \beta=.02$, $p=.770)$ on the sociopolitical control scale. See Figure 6.

\section{Figure 6}

The Interaction Between Sociopolitical Control and National Norm on Voting Intentions in Study 4

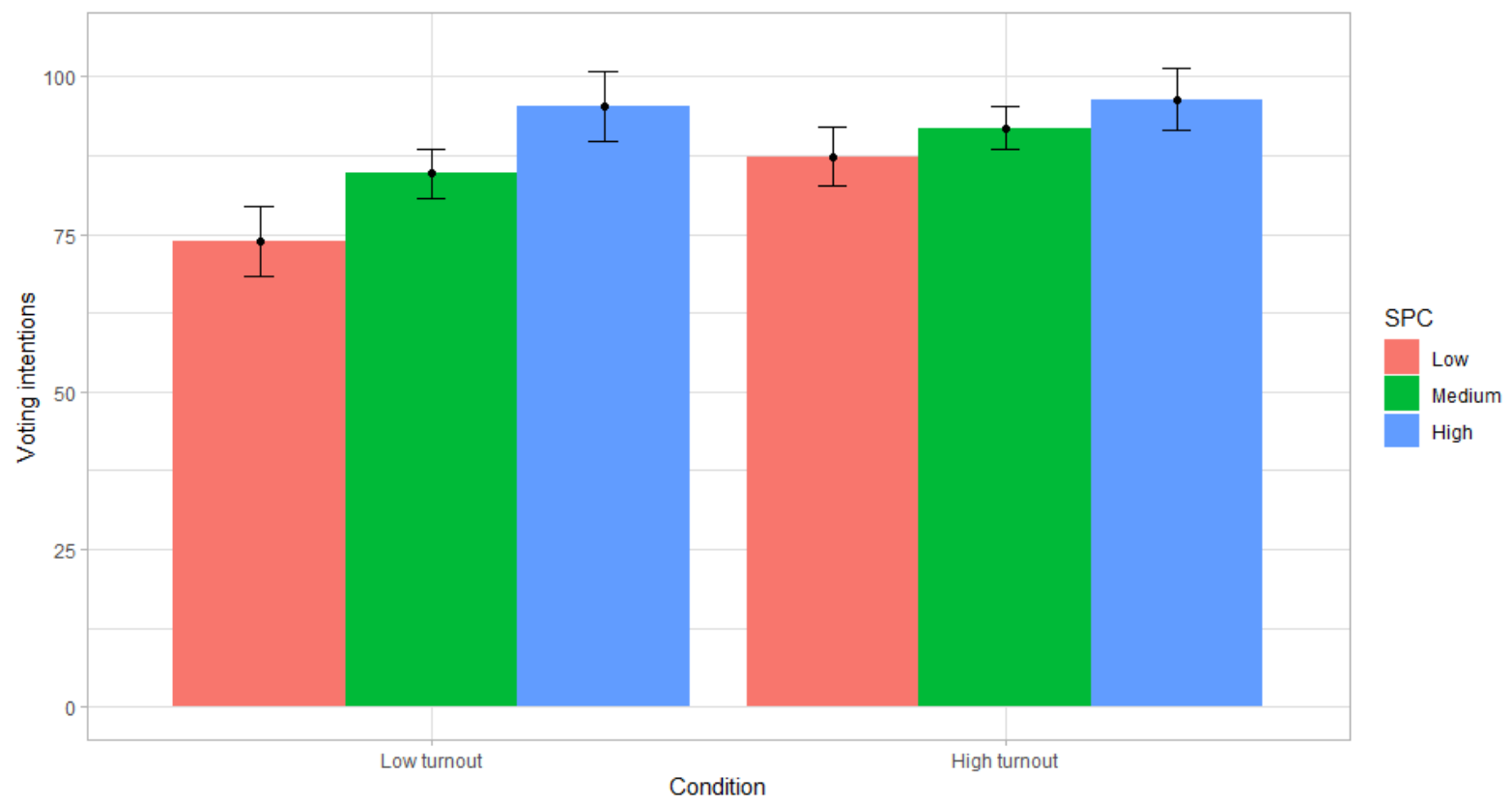

Note: On figures illustrating experimental results we included error bars.

Acquaintances voting norm. To test the second hypothesis, we performed an interaction between perceived acquaintances voting norm and sociopolitical control. The main effect of the ingroup norm was significant $(b=0.36,95 \%$ CI $[0.25,0.47], \beta=.35, p<.001)$. The interaction, which was added in the second step, was significant as well $(b=-0.15,95 \%$ 
CI [-0.29, -0.02], $p=.03, R^{2}$ change $\left.=.01\right)$. Simple slopes analysis showed that the effect of ingroup norm was stronger for participants who scored low $(b=0.47,95 \%$ CI $[0.32,0.62], \beta$ $=.45, p<.001)$, than for those who scored high $(b=0.22,95 \%$ CI $[0.06,0.39], \beta=.21, p=$ $.009)$ on the sociopolitical control scale ${ }^{15}$. See Figure 7.

\section{Figure 7}

The Interaction Between Sociopolitical Control and Perceived Acquaintances Voting Norm on Voting Intentions in Study 4

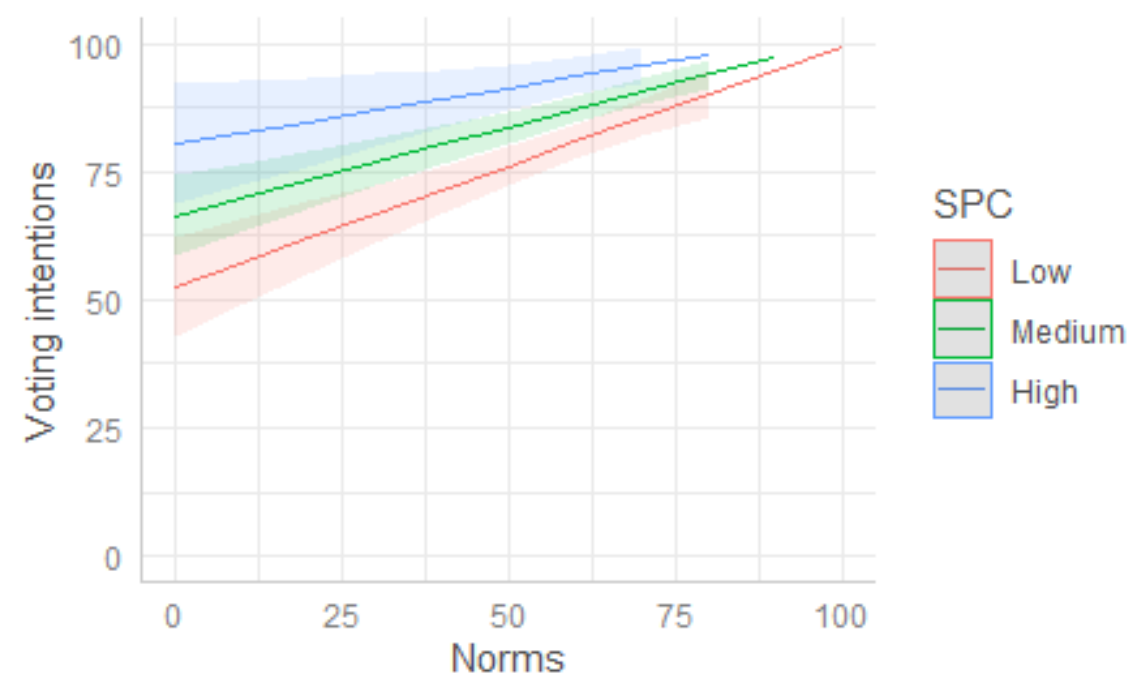

\section{Discussion}

In Study 4 we successfully manipulated the ingroup norm and found support for both predicted hypotheses. First, we showed that participants who were low (vs. high) on sociopolitical control were more likely to conform to the national norm in terms of voting intentions. Second, we replicated the pattern of the results observed in studies 1-3 showing that participants with low levels of sociopolitical control relied more strongly on norms among acquaintances when making a decision on whether to vote or not. One limitation of

\footnotetext{
${ }^{15}$ Reported analyses for norm among friends as a predictor were conducted on the data collapsed across conditions. When we repeated analyses separately for each condition, the interactions became non-significant. The lack of significance was probably due to not enough power to detect the effect in the split sample.
} 
this study was, however, that we observed a ceiling effect for voting intentions among high SPC individuals. In the next study we wanted to address two issues: first, whether our results replicate in a different cultural context, and second, whether the same pattern of results can be obtained while avoiding ceiling effects.

\section{Study 5}

In the final study we intended to replicate the main effect of increased conformity to ingroup norms among low SPC participants in a different cultural context, namely in Southern America (Chile). We also chose this context because, in the past, turnout for regional elections in Chile was relatively low, which offered a chance to avoid ceiling effects observed in Study 4. We also aimed at gathering more experimental evidence for our hypothesis, and therefore, similar to Study 4, we not only measured the ingroup norm but we also manipulated it. Finally, we wanted to check whether higher compliance to ingroup norms appears not only for descriptive norms (which was the area of interest for most studies conducted so far in the context of voting, e.g., Gerber \& Rogers, 2009; Panagopoulos, 2013), but also for injunctive ones. We conducted the study in May 2021, just before the Chilean regional elections (in which mayors, councilors, governors, and constitution writers were chosen). Same as before, we predicted that participants with low (vs. high) sociopolitical control levels would be more likely to conform to the ingroup norms, both measured and manipulated. Preregistration for this study is available at https://osf.io/nqhuv.

\section{Method}

\section{Participants}

We determined the sample size based on the results of Study 4 using the pwr2ppl package (Aberson, 2019) for RStudio. For a regression model with $R^{2}$ increase due to interaction equal to .018 and $R^{2}$ of the whole model equal to .139 , for $\alpha=.05$ and power of .90 we obtained the required number of 500 participants. To account for exclusions we 
recruited more participants. Six hundred fifty-five participants recruited from the Netquest platform completed the procedure of the study in exchange for monetary compensation. We excluded 17 participants who admitted they did not have voting rights and 116 participants who were not able to properly answer the comprehension check. This left us with a final sample of 522 participants ( 211 males, 310 females, 1 other, $\left.M_{\mathrm{age}}=42.66, S D=15.25\right)$.

\section{Materials and procedure}

We started data collection three days before the Chilean regional elections in May 2021.

Spheres of control. At the beginning of the experiment participants filled in two subscales from the spheres of control scale: personal control subscale $(\alpha=.72)$ and sociopolitical control subscale $(\alpha=.64)$.

Manipulation of group norms. Next, we randomly assigned participants to one of the two conditions. In the strong (vs. weak) voting norm condition participants read a fictitious article published presumably by an independent journalistic investigation center CIPER: "Number of Chileans likely to vote is increasing (decreasing)". The full text of manipulation and the pilot study testing this manipulation are described in the Supplementary materials.

Reading check. Next, we asked participants whether they had read the article and allowed only participants who marked "yes" to proceed.

Voting intentions. We measured participants' voting intentions with the same items as in previous studies $(r=.86, \alpha=.92)$.

Perceived voting norm. Afterwards, participants estimated the percentage of their 1) fellow citizens, 2) acquaintances and 3) close friends and family members that would take part in the Chilean regional elections. Additionally, we added one item measuring an injunctive norm: "In your opinion, what percentage of Chileans think it is important to vote in the next elections?". 
Comprehension check. To make sure participants understood the content of the article we asked them to state, according to what they had read, whether voting intentions among Chileans are increasing, decreasing, or are the same. In the final sample, we included only those participants who gave the right answer.

Demographics. We asked participants about their sex, age, education level, socioeconomic status, right to vote and place of residence.

\section{Results}

\section{Sociopolitical control as a moderator}

National norm. Both sociopolitical control and manipulation of ingroup norm (coded as $0=$ weak norm, $1=$ strong norm) had a significant and positive effect on declared voting intentions (Sociopolitical control: $b=10.40,95 \%$ CI [7.51, 13.29], $\beta=.29, p<.001$; ingroup norm: $\mathrm{M}_{\text {weak norm }}=76.60, \mathrm{M}_{\text {strong norm }}=86.76, b=9.70,95 \%$ CI $\left.[4.67,14.72], p<.001\right)$. Next, we tested the interaction between norm and sociopolitical control, which was significant $(b=$ $-8.86,95 \%$ CI $[-14.65,-3.07], p=.003, R^{2}$ change $\left.=.02\right)$. Subsequent analysis revealed that the effect of the manipulation was significant only for participants who scored low $(b=17.30$, 95\% CI [10.26, 24.34], $\beta=.28, p<.001)$, but not high $(b=1.99,95 \%$ CI $[-5.09,9.08], \beta=$ $.03, p=.581)$ on the sociopolitical control scale. See Figure 8. 


\section{Figure 8}

The Interaction Between Sociopolitical Control and National Norm Manipulation on Voting Intentions in Study 5

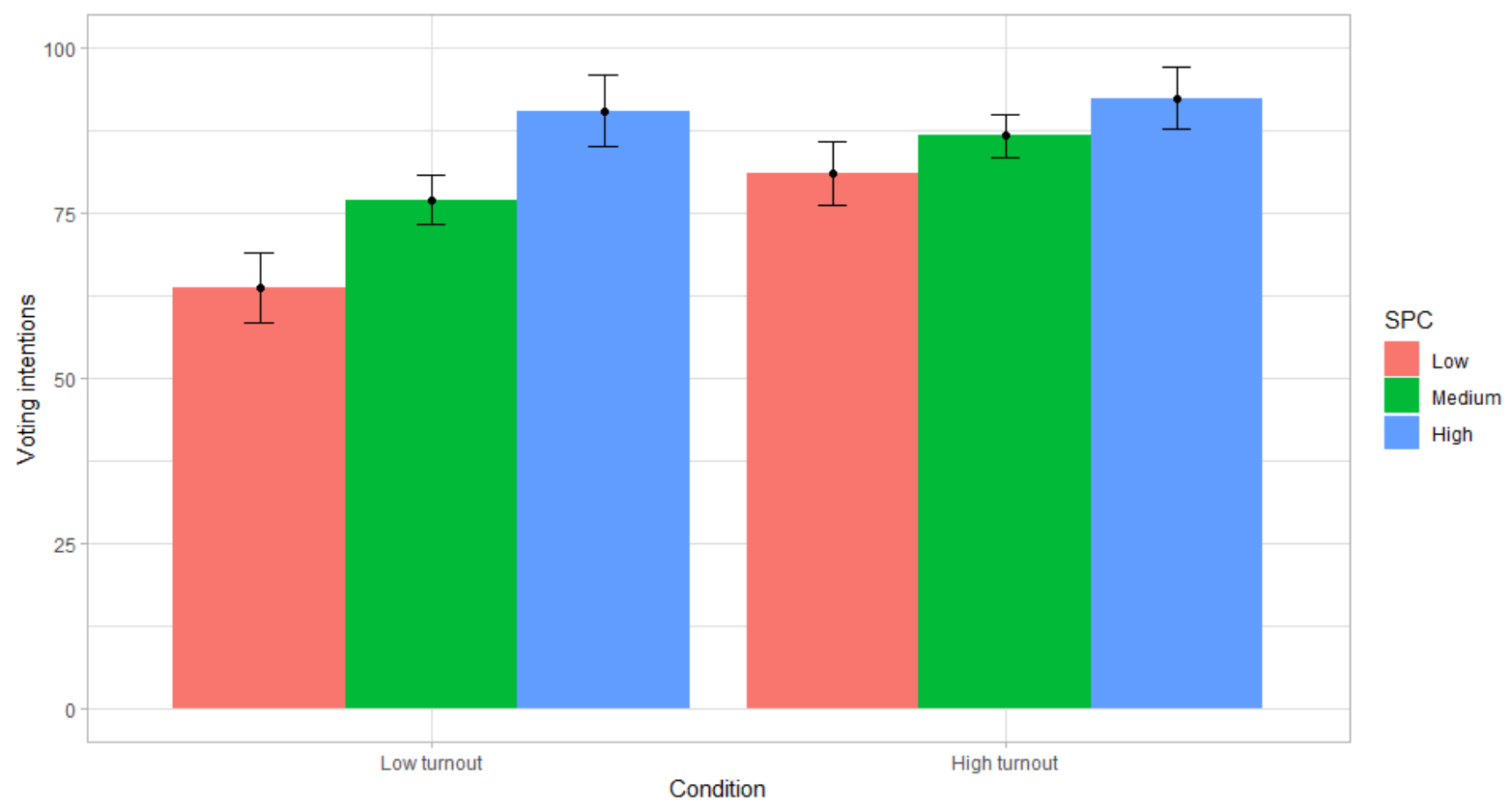

Acquaintances voting norm. To test the second hypothesis, we performed an interaction between perceived acquaintances voting norm and sociopolitical control. The main effect of the ingroup norm was significant $(b=0.71,95 \% \mathrm{CI}[0.63,0.79], \beta=.61, p<.001)$. The interaction, which was added in the second step, was significant as well $(b=-0.14,95 \%$ CI [-0.22, -0.06], $p<.001, R^{2}$ change $\left.=.01\right)$. Simple slopes analysis showed that the effect of ingroup norm was stronger for participants who scored low $(b=0.80,95 \%$ CI $[0.71,0.89], \beta$ $=.68, p<.001)$, than for those who scored high $(b=0.56,95 \%$ CI $[0.44,0.67], \beta=.47, p<$ $.001)$ on the sociopolitical control scale. See Figure 9. The results for participants' close friends and family as well as for measured national norm were significant and had almost an identical pattern (see Supplementary materials). 


\section{Figure 9}

The Interaction Between Sociopolitical Control and Perceived Acquaintances Voting Norm on Voting Intentions in Study 5

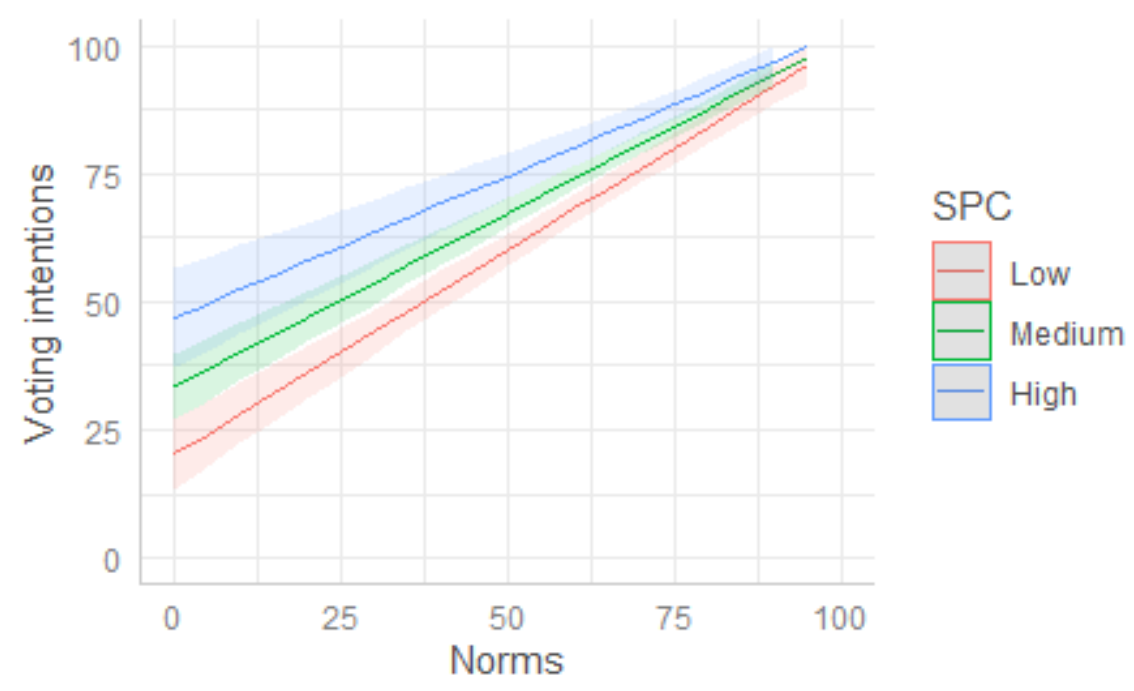

Injunctive national norm. In the very final step we wanted to explore whether we would observe the same interactive effect using an injunctive instead of descriptive ingroup norm. The main effect of the injunctive norm was significant $(b=0.39,95 \%$ CI $[0.28,0.51], \beta$ $=.28, p<.001)$. The interaction between this norm and SPC was significant as well $(b=-0.24$, $95 \%$ CI $[-0.36,-0.13], p<.001, \mathrm{R}^{2}$ change $\left.=.03\right)$. Simple slopes analysis revealed that the effect of ingroup norm was only significant among participants who scored low $(b=0.57$, 95\% CI $[0.43,0.71], \beta=.41, p<.001)$, but not high $(b=0.15,95 \%$ CI $[-0.01,0.31], \beta=.11$, $p=.060)$ on the sociopolitical control scale ${ }^{16}$.

\footnotetext{
${ }^{16}$ Reported analyses for perceived norms as predictors were conducted on the data collapsed across conditions. When we repeated analyses separately for each condition, all the interactions remained significant in the "strong norm" condition, while they became non-significant in the "weak norm condition" (apart from the one with injunctive norm as a predictor). Specifically, in the "strong norm" condition, high SPC participants more often declared they would vote in the elections no matter what the norm was and low SPC participants followed the norm, while in the "weak norm conditions" high SPC participants became more similar to low SPC participants and they also tended to follow the perceived norm.
} 


\section{Discussion}

In Study 5 we replicated the pattern of the results obtained in previous studies using a sample from Southern America (Chile), which points to the generalizability of the findings to yet another sociopolitical context. We again successfully manipulated the national norm and found support for both predicted hypotheses in the context of the next type of elections regional and constitutional ones. First, we showed that participants who were low (vs. high) on sociopolitical control were more likely to conform to the presented national norm in terms of voting intentions. Second, we replicated the pattern of the results observed in studies 1-4 showing that participants with low levels of sociopolitical control rely more strongly on norms among acquaintances when making a decision on whether to vote or not. We also managed to diminish the problem of a ceiling effect among high sociopolitical control participants observed in Study 4. Additionally, we show evidence that the effect appears also when ingroup norm was not descriptive, but injunctive (percentage of Chileans for whom voting is important). This adds to the previous literature, which has mainly concentrated on compliance to norms describing the amount of ingroup members that actually participate in the elections.

\section{Integrative data analysis and results overview}

To compare the relationship between sociopolitical control and two kinds of social norms across the studies in one model and to increase statistical power, we used regression for integrative data analysis (Curran \& Hussong, 2009). For this purpose, we used all the studies where we measured norms both at the level of the whole nation and among participants' acquaintances (Study 1a, 1b, 2, 3 and 5).

After pooling the subsamples into one dataset we obtained a total sample of 1815 participants. When combined in one model, sociopolitical control and norm at the level of acquaintances significantly predicted voting intentions, while the influence of national norm 
was non-significant. After adding in the second step the interactions with ingroup norms measured at two different levels, the interaction between sociopolitical control and acquaintances' voting norm was significant, while an analogical interaction with the national norm as a predictor became non-significant. This result suggests that people with low sociopolitical levels are more likely to follow the norm among their acquaintances and relatives rather than a more general and abstract national norm. A detailed description of these results is included in the Supplementary materials.

We prepared an overview of the results of the research reported in this paper (see Table 1).

Table 1. Overview of the results across studies.

\begin{tabular}{|c|c|c|c|c|}
\hline Study & Elections & Country & $\begin{array}{c}\text { Interaction } \\
\text { with national } \\
\text { norm as an IV }\end{array}$ & $\begin{array}{c}\text { Interaction } \\
\text { with friends' } \\
\text { norm as an IV }\end{array}$ \\
\hline $1 \mathrm{a}$ & European & Poland & $\begin{array}{c}b=-0.51, \\
p<.001 ; \\
R^{2} \text { change }=.03\end{array}$ & $\begin{array}{c}b=-0.23, \\
p<.001 ; \\
R^{2} \text { change }=.02\end{array}$ \\
\hline $1 b$ & European & Spain & $\begin{array}{c}b=-0.08 \\
p=.437 \\
R^{2} \text { change }<.01\end{array}$ & $\begin{array}{c}b=-0.10 \\
p=.087 . \\
\mathrm{R}^{2} \text { change }=.01\end{array}$ \\
\hline 2 & Legislative & Poland & $\begin{array}{c}b=-0.51 \\
p=.014 ; \\
R^{2} \text { change }=.03\end{array}$ & $\begin{array}{c}b=-0.27 \\
p<.001 ; \\
R^{2} \text { change }=.05\end{array}$ \\
\hline 3 & Presidential & Poland & $\begin{array}{c}b=0.02, \\
p=.842 \\
R^{2} \text { change }<.01\end{array}$ & $\begin{array}{c}b=-0.17, \\
p=.005, \\
R^{2} \text { change }=.02\end{array}$ \\
\hline 4 & Legislative & Poland & $\begin{array}{c}b=-7.68, \\
p=.019, \\
\mathrm{R}^{2} \text { change }=.02\end{array}$ & $\begin{array}{c}b=-0.15, \\
p=.03, \\
R^{2} \text { change }=.01\end{array}$ \\
\hline 5 & Regional & Chile & $\begin{array}{c}b=-8.86, \\
p=.003, \\
R^{2} \text { change }=.02\end{array}$ & $\begin{array}{c}b=-0.14, \\
p<.001, \\
R^{2} \text { change }=.01\end{array}$ \\
\hline
\end{tabular}


Note. In Study $1 \mathrm{~b}$ conducted in Spain, the results were significant and in the predicted direction only for the item measuring the probability of voting $(b=-0.20,95 \% \mathrm{CI}[-0.34$, $0.06], p=.004)$, but not for the item measuring the importance of voting $(b<0.01,95 \%$ CI [$0.13,0.13], p=.985)$. For studies $1-3$ we report interactions with measured national norm and for studies 4-5 with manipulation of national norm.

\section{General Discussion}

Across six studies conducted in three countries and in the context of four kinds of elections, we consistently found support for the hypothesis that people who perceive their sociopolitical control as low (vs. high) are more likely to follow ingroup norms when undertaking a decision on whether to vote or not. These results have important theoretical and practical implications. Specifically, they show that the belief that an individual cannot influence the social and political life of their country - termed as low sociopolitical control does not always have to lead to withdrawal from participation in political life. On the contrary, our results suggest that these negative consequences can be avoided when a given person believes that the norm in his or her group is positive and voting is a common behavior, especially amongst their ingroup or reference group members.

This effect could be observed for the national norms, but it was even stronger for perceived norms among participants' acquaintances, supporting previous findings which show a high impact of behaviors present amongst friends and relatives on people's decisions (Christakis \& Fowler, 2013; Gerber et al., 2008). This result is important in the era of social media, suggesting that encouraging people to share information about their participation in elections with their friends may have a strong influence on voting turnout (see also Bond et al., 2012). Additionally, our research shows that under certain conditions (i.e., high political polarization) a national norm seems to no longer be related to voting intentions, as opposed to 
norms among acquaintances. Moreover, we show that the discussed effect is not restricted to European samples, but can also be observed in more collectivistic cultures, such as the Chilean one, addressing this way the need for social sciences to conduct studies that prove generalizability across different contexts (Henrich et al., 2010).

The results of our studies are consistent with findings obtained within the group-based control model (Fritsche et al., 2011, 2013), showing that low levels of control are related to increased norm compliance. However, our findings also provide an important extension of the previous research by demonstrating that this effect also refers to beliefs about control in a specific, sociopolitical context. While the group-based control model assumes that compliance to ingroup norms can be an answer to lack of personal control, our results show that it can be even more the case when a sense of sociopolitical control is low and when given action (e.g. voting) directly addresses the domain in which lack of control appears. Recent research showed the importance of such a match between specific source of controllability and the domain, in which an action takes place (Potoczek et al., 2021).

The results that we obtained could be alternatively explained by the compensatory control theory (Kay et al., 2009), which assumes that participants experiencing a lack of control across whole political spectrum avoid randomness and strive for structure in their environment (de Leon \& Kay, 2020; Landau et al., 2015). It is thus possible that people with low levels of sociopolitical control are more motivated to follow what they perceive as a pattern in their group (i.e., existing social norm) rather than to oppose it. However, our results also point to the fact that norms of specific ingroups (i.e., participants' acquaintances) are more influential than others (i.e., national norms), which supports the idea that not always any kind of structure allows for regaining control, but this process may depend on the importance of and strength of the identification with a given reference group, which supports group-based control model assumptions (Fritsche et al., 2013; Stollberg et al., 2017). 
Our results also add to the research conducted by Gerber and Rogers (2009), who found that some people (i.e., infrequent voters) tend to be more susceptible to the influence of social norms than others (i.e., active voters), by pointing at the specific psychological process that underlies this difference, namely sociopolitical control. Our results correspond with these conclusions, showing that people with high levels of sociopolitical control tend to take part in the elections, irrespective of what the group norms are, while those who do not believe in their influence over sociopolitical issues are more likely to do what the majority of their group members does and they need to be faced with a strong social norm in order to follow it.

Importantly, our findings suggest that negative consequences of sociopolitical uncontrollability (e.g., Kofta et al., 2020) can be potentially avoided when people are surrounded by positive ingroup norms. Specifically, social norms that highlight commitment of group members to participate in political elections can be a constructive and effective way of coping with uncontrollability.

\section{Limitations and Future Research}

One limitation of this research is that experimental evidence showing increased compliance to norms was obtained only using norm manipulation, rather than sociopolitical control manipulation. The decision to manipulate only the former factor was based on research showing that control beliefs, especially those related to such aspects of control as the ability to influence one's social environment, are fairly stable across life (Gatz \& Karel, 1993) as compared to perceived norms, which can be more easily influenced (for a review, see Tankard \& Paluck, 2016). However, future studies are needed to address the possibility of manipulating sociopolitical control beliefs. It would also be beneficial to investigate how a lack of control over politics is related to different existing constructs, such as voter apathy or political self-efficacy. Finally, further research is necessary to answer the question of whether 
social norms influence participants with low levels of sociopolitical control not only in terms of voting intentions, but also in terms of actual voting behavior.

Three important practical conclusions stem from the discussed research. First, those people who do not believe in their influence over sociopolitical issues are especially likely to be influenced by social norms in terms of voting intentions, particularly when the norms are strong and present amongst their acquaintances and friends. Second, the messages promoting voting behavior may be more effective when a clear, positive descriptive norm is presented as opposed to what media and government usually do - highlighting the negative norm. Our research suggests that this second type of message might be counterproductive and lead to political disengagement. Finally, the results of the discussed studies demonstrate that low control over sociopolitical issues does not necessarily mean that one will resign from taking part in the political life of one's own country - this will happen only when he or she believes that this is what others do as well.

So far, the majority of research and evidence-based recommendations on this topic has concentrated on long-term strategies, such us reforming civic education system (Celio et al., 2011), building a sense of voting responsibility among citizens (Borg \& Azzopardi, 2021) or nurturing their interest in politics (White et al., 2000). These solutions - although beneficial and important - may sometimes be too difficult and too demanding to be applied. We propose that perceiving ingroup norms as participatory may increase the willingness to vote among its members experiencing lack of control over politics. We also present initial evidence suggesting that even simple interventions, such as portraying voting norms in a given social group as strong, positive and participatory, may encourage citizens to take part in political elections. 


\section{References}

Aberson, C. (2019). Applied Power Analysis for the Behavioral Sciences. Routledge.

Barth, M., Masson, T., Fritsche, I., \& Ziemer, C.-T. (2017). Closing ranks: Ingroup norm conformity as a subtle response to threatening climate change. Group Processes \& Intergroup Relations, 21(3), 497-512. https://doi.org/10.1177/1368430217733119

Bond, R. M., Fariss, C. J., Jones, J. J., Kramer, A. D. I., Marlow, C., Settle, J. E., \& Fowler, J. H. (2012). A 61-million-person experiment in social influence and political mobilization. Nature, 489(7415), 295-298. https://doi.org/10.1038/nature11421

Borg, M., \& Azzopardi, A. (2021). Political interest, recognition and acceptance of voting responsibility, and electoral participation: young people's perspective. Journal of Youth Studies. https://doi.org/10.1080/13676261.2021.1902963

Celio, C. I., Durlak, J., \& Dymnicki, A. (2011). A Meta-Analysis of the Impact of Service Learning on Students. Journal of Experiential Education, 34(2), 164181. https://doi.org/10.1177/105382591103400205

Christakis, N. A., \& Fowler, J. H. (2013). Social contagion theory: Examining dynamic social networks and human behavior. Statistics in Medicine, 32(4), 556-577. https://doi.org/10.1002/sim.5408

Cialdini, R. B., Demaine, L. J., Sagarin, B. J., Barrett, D. W., Rhoads, K., \& Winter, P. L. (2006). Managing social norms for persuasive impact. Social Influence, 1(1), 3-15. https://doi.org/10.1080/15534510500181459

Condon, M., \& Holleque, M. (2013). Entering politics: General self-efficacy and voting behavior among young people. Political Psychology, 34(2), 167-181

Craig, S. C., Niemi, R. G., \& Silver, G. E. (1990). Political efficacy and trust: A report on the NES pilot study items. Political Behavior, 12(3), 289-314. https://doi.org/10.1007/BF00992337 
Curran, P. J., \& Hussong, A. M. (2009). Integrative data analysis: The simultaneous analysis of multiple data sets. Psychological Methods, 14(2), 81-100. https://doi.org/10.1037/a0015914

Darmofal, D. (2010). Reexamining the Calculus of Voting. Political Psychology, 31(2), 149-174.

de Leon, R., \& Kay, A. C. (2020). Political Ideology and Compensatory Control Mechanism. Current Opinion in Behavioral Science, 34, 112-117

Faul, F., Erdfelder, E., Lang, A.-G., \& Buchner, A. (2007). G*Power 3: A flexible statistical power analysis program for the social, behavioral, and biomedical sciences. Behavior Research Methods, 39(2), 175-191.

Fowler, J. H. (2005). Turnout in a small world. In A. Zuckerman (Ed.), The Social Logic of Politics: Personal Networks as Contexts for Political Behavior (pp. 269-87). Temple University Press.

Fritsche, I., Jonas, E., Ablasser, C., Beyer, M., Kuban, J., Manger, A.-M., \& Schultz, M. (2013). The power of we: Evidence for group-based control. Journal of Experimental Social Psychology, 49(1), 19-32. https://doi.org/10.1016/j.jesp.2012.07.014

Fritsche, I., Jonas, E., Kayser, D. N., \& Koranyi, N. (2010). Existential threat and compliance with pro-environmental norms. Journal of Environmental Psychology, 30(1), 67-79. https://doi.org/10.1016/j.jenvp.2009.08.007

Fritsche, I., Jonas, E., \& Kessler, T. (2011). Collective reactions to threat: Implications for intergroup conflict and for solving societal crises. Social Issues and Policy Review, 5(1), 101-136. https://doi.org/10.1111/j.1751-2409.2011.01027.x

Gailliot, M. T., Stillman, T. F., Schmeichel, B. J., Maner, J. K., \& Plant, E. A. (2008). 
Mortality salience increases adherence to salient norms and values. Personality \& Social Psychology Bulletin, 34(7), 993-1003. https://doi.org/10.1177/0146167208316791

Galinsky, A. D., Magee, J. C., Gruenfeld, D. H., Whitson, J. A., \& Liljenquist, K. A. (2008). Power reduces the press of the situation: Implications for creativity, conformity, and dissonance. Journal of Personality and Social Psychology, 95(6), 1450-1466. https://doi.org/10.1037/a0012633

Gatz, M., \& Karel, M. J. (1993). Individual change in perceived control over 20 years. International Journal of Behavioral Development, 16(2), 305-322. https://doi.org/10.1177/016502549301600211

Gerber, A., Green, D., \& Larimer, C. (2008). Social pressure and voter turnout: Evidence from a large-scale field experiment. The American Political Science Review, 102(1), $33-48$.

Gerber, A. S., \& Rogers, T. (2009). Descriptive social norms and motivation to vote: Everybody's voting and so should you. The Journal of Politics, 71(1), 178-191. https://doi.org/10.1017/S0022381608090117

Hayes, A. (2018). Introduction to mediation, moderation, and conditional process analysis a regression-based approach. Guilford Press.

Henrich, J., Heine, S. J., \& Norenzayan, A. (2010). The weirdest people in the world?. The Behavioral and Brain Sciences, 33(2-3), 61-135. https://doi.org/10.1017/S0140525X0999152X

Jonas, E., \& Fritsche, I. (2012). Follow the norm! Terror management theory and the influence of descriptive norms. Social Psychology, 43(1), 28-32. https://doi.org/10.1027/1864-9335/a000077

Jonas, E., Martens, A., Kayser, D. N., Fritsche, I., Sullivan, D., \& Greenberg, J. (2008). Focus 
theory of normative conduct and terror-management theory: The interactive impact of mortality salience and norm salience on social judgment. Journal of Personality and Social Psychology, 95(6), 1239-1251. https://doi.org/10.1037/a0013593

Karp, J. A., \& Banducci, S. A. (2008). Political efficacy and participation in twenty-seven democracies: How electoral systems shape political behaviour. British Journal of Political Science, 38(2), 311-334. https://doi.org/10.1017/S0007123408000161

Kay, A. C., Whitson, J. A., Gaucher, D., \& Galinsky, A. D. (2009). Compensatory control: Achieving order through the mind, our institutions, and the heavens. Current Directions in Psychological Science, 18(5), 264-268. https://doi.org/10.1111/j.14678721.2009.01649.x

Kofta, M., Soral, W., \& Bilewicz, M. (2020). What breeds conspiracy antisemitism? The role of political uncontrollability and uncertainty in the belief in Jewish conspiracy. Journal of Personality and Social Psychology, 118(5), 900-918. https://doi.org/10.1037/pspa0000183

Lammers, J., Stapel, D. A., \& Galinsky, A. D. (2010). Power increases hypocrisy: Moralizing in reasoning, immorality in behavior. Psychological Science, 21(5), 737-744. https://doi.org/10.1177/0956797610368810

Landau, M. J., Kay, A. C., \& Whitson, J. A. (2015). Compensatory control and the appeal of a structured world. Psychological Bulletin, 141(3), 694-722. https://doi.org/10.1037/a0038703

Lucas, J., \& Lovaglia, M. J. (2014). Perceptions of Ability and Adherence to Rules, Guidelines, and Tradition. In Advances in Group Processes (Vol. 31, pp. 219-240). https://doi.org/10.1108/S0882-614520140000031004

Lüdecke, D. (2018). ggeffects: Tidy Data Frames of Marginal Effects from Regression Models. Journal of Open Source Software, 3(26), 772. doi: 10.21105/joss.00772. 
Milyavsky, M., Kruglanski, A. W., Gelfand, M., Chernikova, M., \& Pierro, A. (2020, June 3). People Who Need People (and Some Who Think They Don't): On Compensatory Personal and Social Means of Goal Pursuit. https://doi.org/10.31234/osf.io/huyb4 Nickerson, D. W. (2008). Is Voting Contagious? Evidence from Two Field Experiments. American Political Science Review, 102(1), 49-57. https://doi.org/10.1017/S0003055408080039

Panagopoulos, C. (2013). Positive Social Pressure and Prosocial Motivation: Evidence from a Large-Scale Field Experiment on Voter Mobilization. Political Psychology, 34(2), 265-275.

Paulhus, D., \& Christie, R. (1981). Spheres of Control: An Interactionist Approach to Assessment of Perceived Control. In H. M. Lefcourt (Ed.), Research with the Locus of Control Construct (pp. 1-161). Academic Press.

Paulhus, D. L., \& Van Selst, M. (1990). The Spheres of Control Scale: 10 yrs of research. Personality and Individual Differences, 11(10), 1029-1036. https://doi.org/10.1016/0191-8869(90)90130-J

Pollock, P. H. (1983). The Participatory Consequences of Internal and External Political Efficacy: A Research Note. The Western Political Quarterly, 36(3), 400-409. JSTOR. https://doi.org/10.2307/448398

Potoczek, A., Bukowski, M., Jaśko, K., Czepluch, F., Fritsche, I., Jugert, P., \& Kossowska, M. (2021). Acting collectively against air pollution: when does control threat mobilize environmental activism [Manuscript submitted for publication].

Rodríguez, R., \& Moya, M. (1998). España vista desde Andalucia. Estereotipos e identidad. Psicología Política, 16, 27-48.

Rothbaum, F., Weisz, J. R., \& Snyder, S. S. (1982). Changing the world and changing the 
self: A two-process model of perceived control. Journal of Personality and Social Psychology, 42(1), 5-37. https://doi.org/10.1037/0022-3514.42.1.5

Skinner, E. A. (1996). A guide to constructs of control. Journal of Personality and Social Psychology Journal of Personality and Social Psychology, 71(3), 549-570. https://doi.apa.org/doiLanding?doi=10.1037/0022-3514.71.3.549

Stollberg, J., Fritsche, I., Barth, M., \& Jugert, P. (2017). Extending control perceptions to the social self: Ingroups serve the restoration of control. In M. Bukowski, I. Fritsche, A. Guinote, \& M. Kofta (Eds.), Coping with lack of control in a social world (pp. 133$150)$.

Stollberg, J., Fritsche, I., \& Jonas, E. (2017). The groupy shift: Conformity to liberal in-group norms as a group-based response to threatened personal control. Social Cognition, 35(4), 374-394. https://doi.org/10.1521/soco.2017.35.4.374

Tankard, M. E., \& Paluck, E. L. (2016). Norm perception as a vehicle for social change. Social Issues and Policy Review, 10(1), 181-211. https://doi.org/10.1111/sipr.12022

Turner, J. C., Hogg, M. A., Oakes, P. J., Reicher, S. D., \& Wetherell, M. S. (1987). Rediscovering the social group: A self-categorization theory. Basil Blackwell.

Twenge, J. M., Zhang, L., \& Im, C. (2004). It's beyond my control: A cross-temporal meta analysis of increasing externality in locus of control, 1960-2002. Personality and Social Psychology Review, 8(3), 308-319. https://doi.org/10.1207/s15327957pspr0803_5

White, C., Bruce, S., \& Ritchie, J. (2000). Young people's politics Political interest and engagement amongst 14-24 year olds. Joseph Rowntree Foundation.

Wickham, H. (2016). ggplot2: Elegant Graphics for Data Analysis. Springer-Verlag New York, https://ggplot2.tidyverse.org. 